\title{
Thickness of the epithelium and the inflammatory cell infiltrate in oral lichen planus. A morphometric study
}

\author{
Ramya VV', Nandini $\mathrm{DB}^{2}$, Praveen $\mathrm{SB}^{3}$, Madhushankari GS ${ }^{4}$
}

Post graduate student ${ }^{1}$, Professor ${ }^{2}$, Reader $^{3}$, Professor \& Head ${ }^{4}$

Department of Oral Pathology \& Microbiology, College of Dental Sciences, Davangere.

\begin{abstract}
:
Background: Oral lichen planus is a chronic mucocutaneous disease of uncertain etiology. Inflammatory cell infiltrate plays an important role in pathogenesis of oral lichen planus. It is said that hyperplastic epithelium is seen where the inflammatory cell infiltrate is mild while beneath atrophic epithelium dense inflammatory cell infiltrate is evident. Studies have shown negative correlation between thickness of the epithelium and thickness of inflammatory cell infiltrate. Morphometric studies in oral lichen planus are very scanty and have been performed using stage micrometer and eye piece graticule. Using Image Analysis Software can avoid inter-observer variations which has not been done till date.
\end{abstract}

Aim and Objectives: The present study aimed at evaluating thickness of epithelium and thickness of inflammatory cell infiltrate and to determine any existing relation between the same using Image Analysis Software. Other histopathologic features were also evaluated.

Materials and method: 58 confirmed cases of oral lichen planus from buccal mucosa were retrieved from department archives. $6 \mu$ thick sections were stained with Hematoxylin and Eosin. Six non-overlapping fields were selected randomly from each section and photomicrographs were captured under 4x objective using Trinocular Research Microscope. Morphometry was done using Image Analysis Software and data was stored in Microsoft excel for statistical analysis.

Results: In present study the mean of epithelium thickness was 281.2059 and inflammatory cell infiltrate thickness was 330.2540. An inverse correlation was observed. As the thickness of inflammatory cell infiltrate increased there was a decrease in thickness of epithelium (Coefficient -0.156).

Conclusion: Thickness of the epithelium may vary according to the site, however in this study all cases were from buccal mucosa. Inflammatory cell infiltrate influences overlying thickness of epithelium and determines its nature.

Key words: Oral lichen planus, epithelium thickness, inflammatory cell infiltrate, melanin incontinence, civatte bodies.

\section{Introduction}

Oral lichen planus is a chronic mucocutaneous disease of uncertain etiology. Clinically it manifests as various forms and histologically characterized by liquefactive degeneration of basal keratinocytes and sub epithelial chronic inflammatory cell infiltrate. Reduced epithelial thickness is a common characteristic feature of oral lichen planus. ${ }^{1}$ Changes in epithelium is believed to be initiated by inflammatory cells that produce an array of cytokines and growth factors which are capable of affecting epithelial cell growth and differentiation. ${ }^{2}$ This in turn is believed to influence the clinical manifestations of oral lichen planus, by producing alterations in the overlying epithelium.

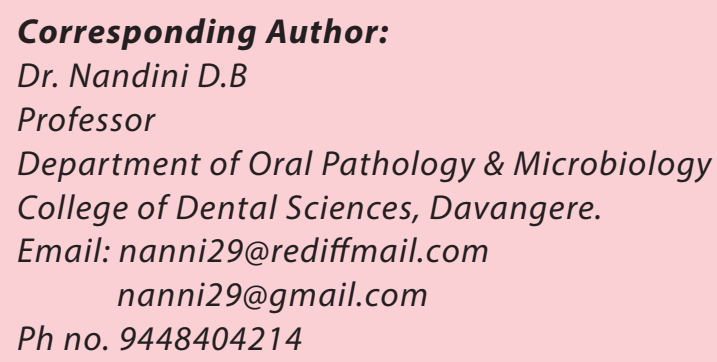

The present study was aimed at evaluating the thickness of epithelium and inflammatory cell infiltrate and also to determine any existing relation between the same using Image Analysis Software and other histopathologic features were also evaluated.

\section{Methodology}

58 confirmed cases of oral lichen planus all from buccal mucosa were retrieved from the department archives. $6 \mu$ thick sections were obtained from paraffin embedded tissue blocks and stained with Hematoxylin and Eosin. All cases fulfilling following histologic criteria were selected and erosive forms were excluded from the study.

\section{Histologic Diagnostic criteria}

- Liquefactive degeneration of basal cell layer

- Presence of well-defined sub epithelial band like inflammatory cell infiltrate

- Absence of epithelial dysplasia 
Six non-overlapping fields devoid of artifacts were selected randomly from each section and photomicrographs were captured under $4 \mathrm{x}$ objective using Trinocular Research Microscope. Thickness of the epithelium from the surface perpendicular to the basement membrane and the thickness of dense inflammatory cell infiltrate beneath the basement membrane from the same region were measured in all the six fields using Image Analysis Software (Figure 1). All the measurements were in microns and were stored in Microsoft Excel. The mean of all the six measurements for each case was calculated. Additional features like nature of epithelium, presence/absence of hyperkeratosis, nature of rete ridges, presence/absence of civatte bodies, melanin incontinence, infiltration of lymphocytes into epithelium and presence/absence of perivascular infiltrate were also observed (Table 1).

Statistical analysis was performed using SPSS $20^{\text {th }}$ version Karl Pearson Correlation Coefficient test to analyse the relationship between thickness of epithelium and inflammatory cell infiltrate in oral lichen planus.

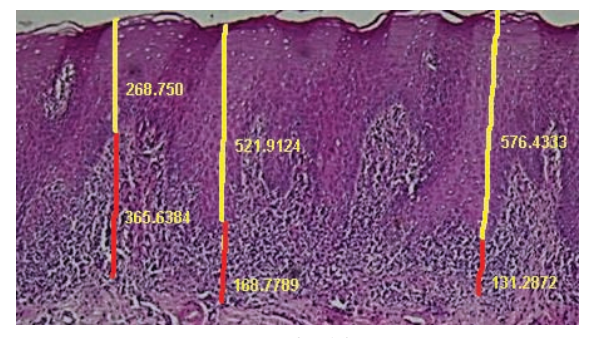

Fig 1A

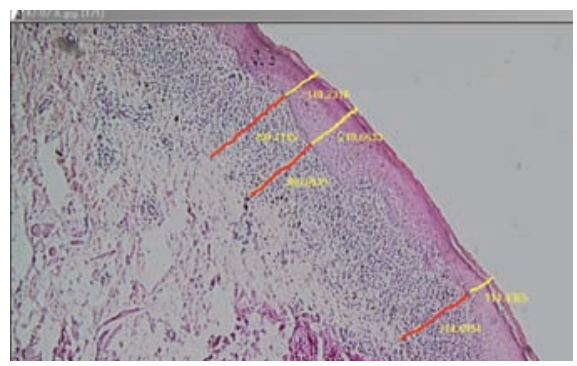

Fig 1B

Fig 1: Photomicrograph showing morphometric measurements in hyperplastic (A) and atrophic epithelium (B). (H \& E stain, 5x)
Table 1: Showing other histological features in the epithelium and connective tissue

\begin{tabular}{|c|c|}
\hline Histological features & $\begin{array}{c}\text { Percentage }(\%) \text { of cases showing the } \\
\text { features }\end{array}$ \\
\hline Epithelial hyperplasia and Acanthosis & $31 \%$ \\
\hline Atrophic Epithelium & $24 \%$ \\
\hline Hyperplastic and Atrophic epithelium & $10 \%$ \\
\hline $\begin{array}{l}\text { Epithelium showing hyperplasia, } \\
\text { acanthosis and atrophic }\end{array}$ & $5 \%$ \\
\hline Hyperkeratosis & $\begin{array}{rr}63 \% & \text { Parakeratosis-53\% } \\
& \text { Orthokeratosis-10\% }\end{array}$ \\
\hline Rete ridges & $\begin{array}{l}\text { Elongated- } 44 \% \\
\text { Serrated-22\% } \\
\text { Saw tooth-3\% } \\
\text { Flat epithelium-connective tissue interface } \\
-31 \%\end{array}$ \\
\hline Presence of civatte bodies & $\begin{array}{r}\text { In epithelium- 24\% } \\
\text { Connective tissue- } 5 \% \\
\text { Both-3\% }\end{array}$ \\
\hline Predominant inflammatory cell type & $\begin{array}{l}\text { Lymphocytes-86\% } \\
\text { Mixed inflammatory cells-14\% }\end{array}$ \\
\hline Melanin incontinence & Present in 69\% \\
\hline Lymphocytic Infiltration into epithelium & $\begin{array}{l}\text { Basal layer-71\% } \\
\text { Middle third of epithelium-2\% }\end{array}$ \\
\hline Perivascular infiltration & Present in $5 \%$ \\
\hline
\end{tabular}

Graph 1: Showing mean thickness of epithelium and the inflammatory cell infiltrate (in microns)

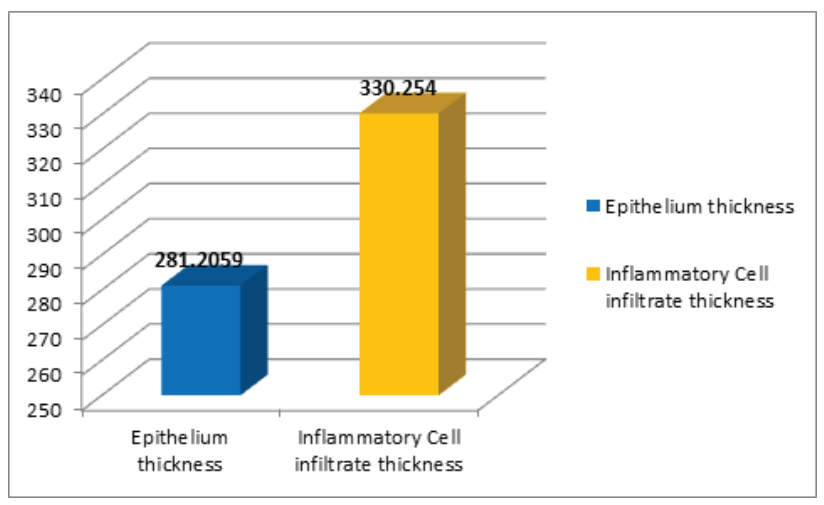

\section{Results}

A total of 58 confirmed cases of oral lichen planus were analyzed including 26 males (44\%) and 32 females (56\%). The age of the patients ranged from 16-74 years with mean age of 37 \pm 10 years. In the present study the mean epithelial thickness was $281.2 \mu \pm 109.04$ and the thickness of sub epithelial inflammatory cell infiltrate was $330.25 \mu$ \pm 101.35 (Graph 1).A negative correlation was observed between thickness of the epithelium and thickness of the inflammatory cell infiltrate (correlation coefficient -0.156). As the thickness of inflammatory cell infiltrate increased, there was reduction in the thickness of epithelium. 


\section{Discussion}

Oral lichen planus is a chronic inflammatory condition presenting as a bilateral symmetrical lesion commonly affecting buccal mucosa.

Clinically it manifests as reticular, plaque, erosive and atrophic forms. It commonly affects middle aged women. In the present study mean age of subjects was $37 \pm 10$ years and female predominance $(56 \%)$ was also evident. This was in accordance with previous studies.

Etiopathogenesis of oral lichen planus involves cell-mediated autoimmune damage to basal keratinocytes involving disruption of epithelial basement membrane zone resulting in reduced thickness of epithelium. ${ }^{1}$ Interaction between lymphocytes and keratinocytes is important in the pathogenesis of lichen planus. Balance between proliferating and opposing influences of various cytokines have overall effect on keratinocytes thus influencing epithelial atrophy and hyper-proliferation which influences clinical presentation. ${ }^{2,3,4}$

The present study revealed an inverse relationship between epithelial thickness and thickness of inflammatory cell infiltrate which is in accordance with the study done by Balan et al. ${ }^{4}$

Bloor et al reported that the alteration in epithelial thickness was due to imbalance between cellular proliferation and apoptosis. ${ }^{5}$ Study done by Doddawad et al on the role of apoptotic cells in oral lichen planus also showed that as the number of apoptotic cells increased there was increase in thickness of lymphocytic infiltration but the epithelial thickness was reduced. ${ }^{6}$

Mast cell degranulation releases various cytokines which causes necrosis of basal keratinocytes and degeneration of basement membrane there by altering thickness of the epithelium. According to Walsh et al, mast cell mediators such as tumour necrosis factor alpha and serine proteases produce a potent effect on epithelial cells. $^{7}$

Jontell reported that mild degree of inflammation may provoke the epithelium to produce hyperkeratosis where as more intense inflammation will lead to partial or complete deterioration of the epithelium resulting in atrophy, erosion or ulceration in the epithelium. ${ }^{8}$

Bagan et al showed that the thickness and length of the epithelium is greater in the reticular forms than in atrophic and erosive forms. ${ }^{9}$ Plaque form is similar to reticular form showing hyperkeratosis in combination with acanthosis as reported by De Rossi et al. ${ }^{10}$

According to Mitamura et al, in early phase of lichen planus there is predominance of CD4 positive T-lymphocytes and as the disease progresses there are more CD8 positive T-cells producing a potent cytotoxic effect resulting in reduced thickness of epithelium in the later stages of the disease. ${ }^{11}$

Immuno histochemical assessment of proliferating cell nuclear antigen (PCNA) in various clinical forms of lichen planus done by Mitamura et al showed higher expression of PCNA in reticular and plaque forms ${ }^{11}$ where as study by Pramod et al reported higher expression in erosive form. ${ }^{12}$ These studies suggested the possibility of alterations in cell differentiation mechanism.

Other histological features were also observed in our study. Epithelial hyperplasia and acanthosis was evident in $31 \%$ cases while atrophy was seen in $24 \%$ of cases. Both hyperplasia and atrophy was observed in $10 \%$ cases (Figure 2) and 5\% cases revealed hyperplasia, acanthosis and atrophy together. This is in accordance with the study done by Gonzalez et al who reported that hyperplasia was noticed in majority $(59 \%)$ of cases in reticular forms. ${ }^{13}$

Hyperkeratosis was seen in $63 \%$ of cases in which $53 \%$ showed parakeratosis and $10 \%$ of cases showed orthokeratosis (Figure 3) which is in accordance with findings of Gonzales et al who reported about $69 \%$ of hyperkeratosis in their study. ${ }^{13}$ Hyperkeratosis may be due to moderate expression of $\mathrm{Bcl}-\mathrm{x}$ gene in kerationocytes resulting in proliferation which is reported by Dekker NP et al. ${ }^{14}$

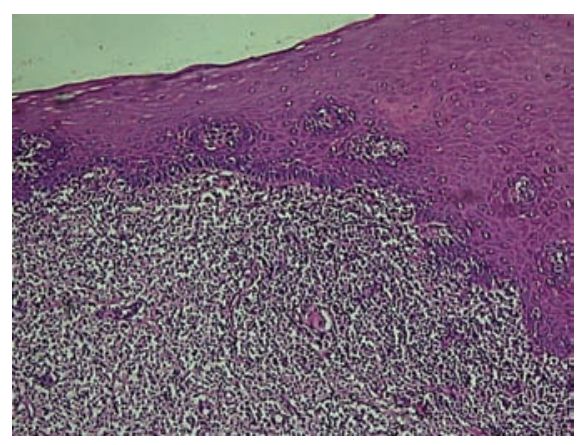

Fig 2: Photomicrograph showing both atrophic and hyperplastic epithelium (H \& E stain, 10x)

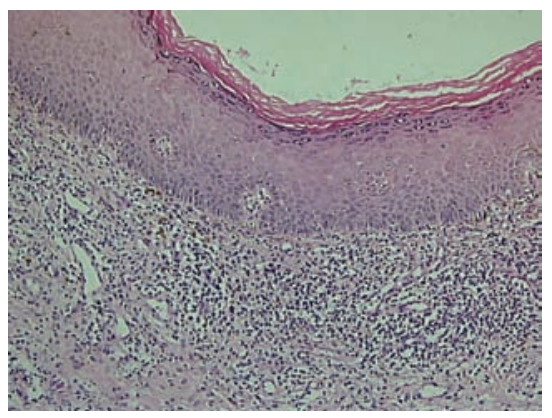

Fig 3: Photomicrograph showing hyperkeratosis (H \& E stain, 10x) 
We observed serrated rete ridges in 22\% of cases, $44 \%$ showed elongated and 3\% of cases showed typical saw tooth rete ridges (Figure 4) and flat interface between epithelium and connective tissue was reported in 31\% of cases. Aminzadeh et al has reported that $53 \%$ of cases showed saw tooth rete ridges but in our study typical saw tooth appearance was seen in only about $3 \%$ of cases and the serrations are produced because of the infiltration of lymphocytes into epithelium. ${ }^{15}$

We observed civatte bodies in 33\% of cases. 24\% of cases showed in epithelium, $5 \%$ in connective tissue and $3 \%$ showed in both. Presence of civatte bodies is also a characteristic finding in lichen planus most commonly seen in skin lesions. These are produced by damaged basal keratinocyte and identified as rounded, homogenous and eosinophilic masses scattered within in the epithelium and connective tissue (Figure 5). ${ }^{16}$

Melanin incontinence was observed in $69 \%$ of cases (Figure 6). This is attributed to lymphocytic infiltration into basal layer of epithelium resulting in destruction of basal cells and ingestion of melanin pigment by macrophages which may be responsible for pigmentation most commonly observed in oral lichen planus. ${ }^{17}$ The other possible mechanism is Gama amino butyric acid (GABA) imbalance in brain tissue during stress and anxiety which increases the production of melanocytes as reported by Anjum R et al. ${ }^{18}$

All cases showed band of inflammatory cell infiltrate however in $71 \%$ of cases there was an extension of inflammatory cell infiltrate into the basal layer of epithelium (Figure 7). Perivascular inflammatory infiltrate was noticed only in 5\% of cases and presence of mixed inflammatory infiltrate which includes lymphocytes and plasma cells was noticed in $14 \%$ of cases (Figure 8) which is a similar finding reported in a study done by Gonzalez et al in which they observed $2 \%$ of cases showing peri vascular infiltrate and plasma cells were noticed in $20 \%$ of cases. ${ }^{13}$

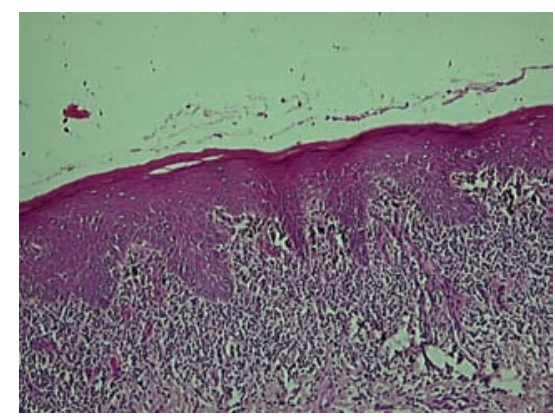

Fig 4: Photomicrograph showing saw tooth rete ridges ( $\mathrm{H} \& \mathrm{E}$ stain, 10x)

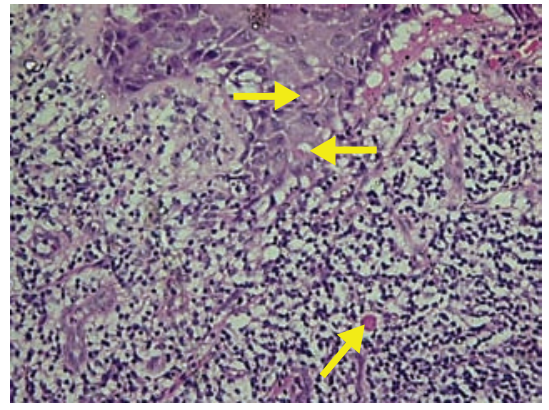

Fig 5: Photomicrograph showing civatte bodies in epithelium and connective tissue (yellow arrows) (H \& E stain, 20x)

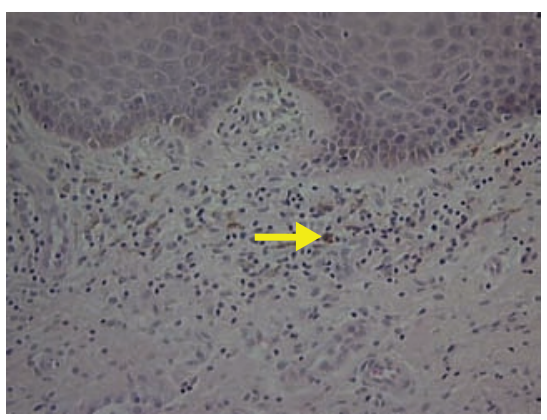

Fig 6: Photomicrograph showing melanin incontinence. (H \& E stain, 40x)

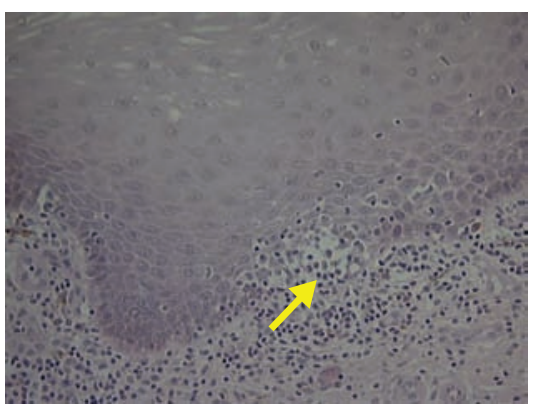

Fig 7: Photomicrograph showing extension of inflammatory cell infiltrate into the basal layer of epthelium

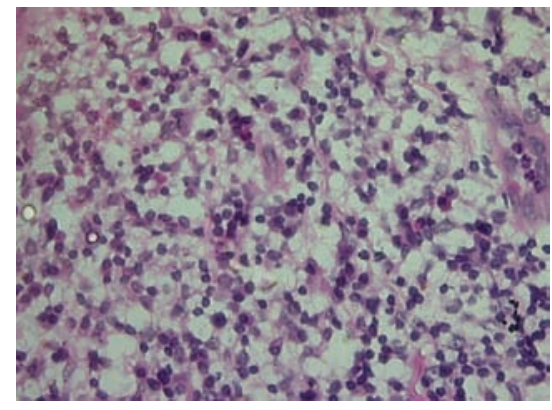

Fig 8: Photomicrograph showing plasma cells and lymphocytes

(H \& E stain, 40x) 


\section{Conclusion}

Hyperplasia, acanthosis, hyperkeratosis are usually observed phenomena in the epithelium in oral lichen planus. The underlying inflammatory cell infiltrate influences the nature of epithelium as observed in this morphometric study.

\section{References}

1. Zhao ZZ, Savage NW, Sugerman PB, Walsh LJ. Mast cell/T cell interactions in oral lichen planus. J Oral Pathol Med. 2002;31:189-195.

2. Yamamoto T, Osaki T. Characteristic cytokines generated by keratinocytes and mono nuclear infiltrates in oral lichenplanus. J Invest Dermatol. 1995; 104:784-88.

3. Sugerman PB, Savage NW, Walsh LJ, Zhao ZZ, Zhou XJ, Khan A, et al. The pathogenesis of oral lichen planus. Crit Rev Oral Biol Med. 2002;13(4):350-65.

4. Balan U, Gonslaves N, Jose M. A quantitative evaluation of epithelium and inflammatory infiltrate of lichen planus and lichenoid reactions. Oral and Maxillofacial Pathology Journal. 2012 Jul;3(2). 233-237

5. Bloor BK, Malik FK, Odell EW, Morgan PR. Quantitative assessment of apoptosis in oral lichen planus. Oral Surg Oral Med Oral Pathol Oral Radiol Endod. 1999;88:187-95.

6. Doddawad VG. Histopathological analysis of apoptotic cell count and its role in oral lichen planus. J Oral Maxillofac Pathol. 2014 Jan;18(1):42-5.

7. Walsh LJ, Savage NW, Ishii T, Seymour GJ. Immunopathogenesis of oral lichen planus. J Oral Pathol Med. 1990;19:389-96.

8. Jontell M. Oral lichen planus- the controversy continues. Oral Dis. 2010;16:506.

9. Bagan JV, Urizar JM, Masanet AM, Diago MP, Vallejo MJ. A morphometric study of 74 cases of oral lichen planus. Rev Stomatol Chir Maxillofac. 1991;92:265-68.
10. DeRossi SS, Ciarrocca KN. Lichen planus, lichenoid drug reactions and lichenoid mucositis. Dent Clin N Am. 2005;49:77-89.

11. Mitamura J, Onodera K, Ooya K. Histopathological and immunohistochemical study of oral lichen planus in the buccal mucosa: relationship between clinicopathological features and histometrical analysis. Oral Med Pathol. 2008;13:1-6.

12. Pramod RC, Pandit S, Desai D, Suresh KV, Ingaleshwar PS, Shetty SJ, Ahamad S. Immunohistochemical assesment of proliferating cell nuclear antigen protein expression in Plaque, reticular and erosive types of oral lichen planus. Ann Med Health Sci Res. 2014 Aug;4(4):598-602.

13.Gonzalez FF, Alvarez RV, Lopez DR, Vila PG, Gracia AG, Rey JM. Histopatholgical findings in oral lichen planus and their correlation with the clinical manifestations. Med Oral Pathol Oral Cir Bucal. 2011;16(5):641-6.

14.Dekker NP, Lozada-Nur F, Lagenaur LA, Macphail LA, Bloom CY, Regezi JA. Apoptosis associated marker in oral lichen planus. J Oral Pathol Med. 1997;26:170-5.

15.Aminzadeh A, Jahanshahi G, Ahmadi M. Aretrospective comparative study on clinic-pathologic features of oral lichen planus and oral lichenoid lesions. Dental Research Journal. 2013 Mar;10(2):168-72

16.Pranay T, Kumar AS, Chhabra S. Civatte bodies: a diagnostic clue. Indian J Dermatol. 2013 Jul;58(4):327.

17.Cawson RA. Treatment of oral lichen planus with betamethasone. Br Med J 1986;1:86-89.

18.Anjum R, Singh J, Kudva S. A clinicohistopathogic study and probable mechanism of pigmentation in oral lichen planus. World Journal of Dentistry 2012 Dec;3(4):330-04.

\section{How to cite this article:}

Ramya VV, Nandini DB, Praveen SB, Madhushankari GS. Thickness of the epithelium and the inflammatory cell infiltrate in oral lichen planus. A morphometric study. CODS J Dent 2014;6;78-82

Source of support: Nil. Conflict of interest: None Declared. 